\title{
EVALUATION OF THIN BED USING RESISTIVITY BOREHOLE AND NMR IMAGING TECHNIQUES \\ *Eshimokhai, S. ${ }^{1}$ Akhirevbulu, O.E. ${ }^{1}$ and Osueni, L. ${ }^{2}$ \\ DOI: http://dx.doi.org/10.4314/ejesm.v4i4.11
}

Received November $30^{\text {th }} 2011$; accepted January $10^{\text {th }} 2012$

\begin{abstract}
In the study of sedimentary units to evaluate thin beds, there lie a lot of uncertainties, primarily, sand, shale or their combination in terms of their petrophysical properties and lateral extant. Good thin beds are capable of yielding a reasonable amount of hydrocarbon if discovered and evaluated. Regrettably, most thin beds are usually bypassed if direct log interpretation techniques are applied in their evaluation due to their low vertical resolutions and ability to only characterize an average of multiple beds which often result to a significant under estimation of oil and gas in the sedimentary unit. To better characterize thin beds and maximize reservoir potential, the resistivity borehole imaging and NMR techniques were adopted in this research study. In addition, the Thomas Stieber equations using laminated sand-shale sequence were employed in calculating parameters such as sand porosity, hydrocarbon saturation and shale volume. Results show that at depths of about 4350m and 4500m (Fig. 2), thin beds were identified, whereas, the conventional logs identified the points as spikes of sand. The NMR imaging technique further confirms the presence of hydrocarbon in the thin beds. It is therefore suggested that the resistivity borehole imaging and NMR techniques should be employed in characterizing thin beds since their use in this study yielded results that are reliable and dependable.
\end{abstract}

Keywords: Thin bed, Borehole image, Sand laminae, Conventional logs, lateral resistivity, Vertical resistivity.

\section{Introduction}

Thin beds include all geological beds and laminae less than about 2 feet thick. Saxena et al. (2006). In Petrophysical sense, "thin beds" are sedimentary units whose thickness is below the vertical resolution of standard logging tools (e.g. Gamma ray, Density, Neutron, Resistivity, and Sonic logs).

This means that each logging tool has its own definition of thin beds starting from $2-4 \mathrm{ft}$ in sonic and deep resistivity to 0.5 in in microimagers. Hence, most logging tools lack the capability to resolve resistivity values for the individual beds of sand and shale; instead they give an average resistivity measurement over the thin bedded sequence, (Saxena and Klimentos, 2004), Claverie et al. (2007).

In a seemingly ever growing number of fields, the petrophysicists are often confronted by the challenge of evaluating thinly bedded formation sequences (i.e. beds whose thickness is below the resolution of most of the contractor "standard" open hole logging tools). The evaluation of such

${ }^{1}$ Department of Physics, Ambrose Alli University Ekpoma, Edo State, Nigeria.

${ }^{2}$ Edo State College of Agriculture Iguoriakhi (Agenebode Campus) Agenebode, Nigeria.

Corresponding email: ekkunna@yahoo.com beds is indeed a challenge as more often than not the available wireline data does not provide anywhere near sufficient resolution to enable a proper evaluation of such beds. At best, the interval may be cored and indications of hydrocarbons detected. At worst, the interval could be totally over-looked due to misinterpretation and business opportunities missed.

One of the common methods to derive water saturation is from resistivity. The non-linear response of the resistivity to the volume and distribution of shale imparts a strong effect on the measured average resistivity of the formation. So, the conventional interpretation methods lead to significant under estimation of results. To overcome this problem, first we have to understand why the conventional logging tools are not able to identify and quantify the laminated shaly sands; i.e.

1. Resolution of the tool is less than the thin beds.

2. Conventional Resistivity is dominated by high conductivity shale layers. 


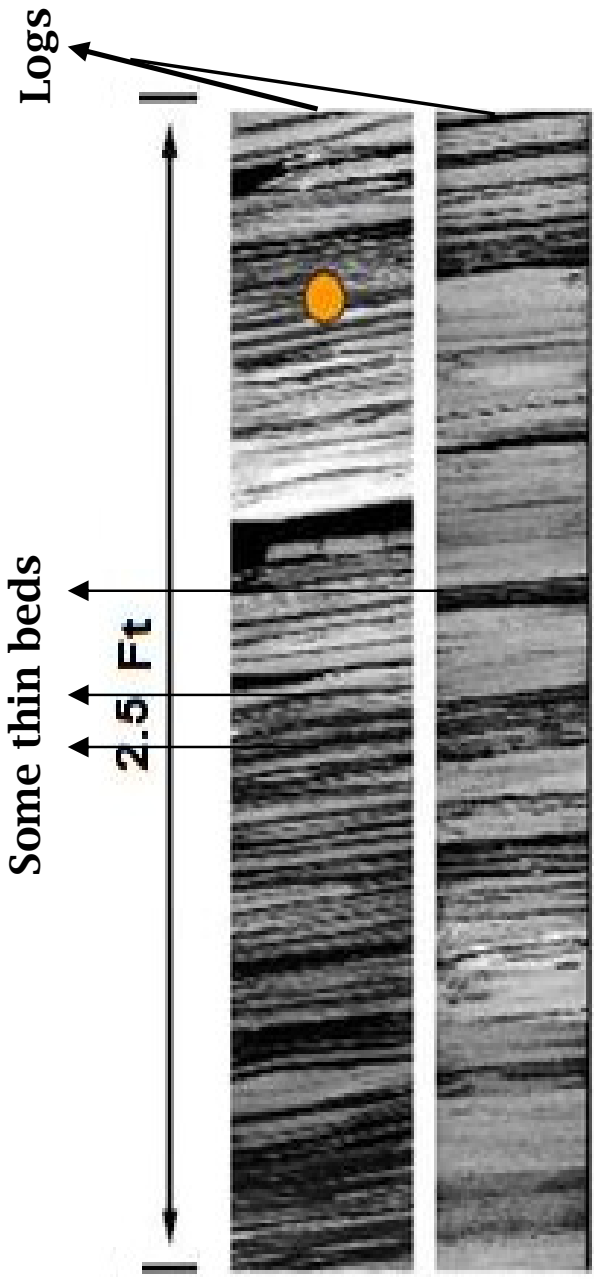

Fig.1. Log showing thin beds.

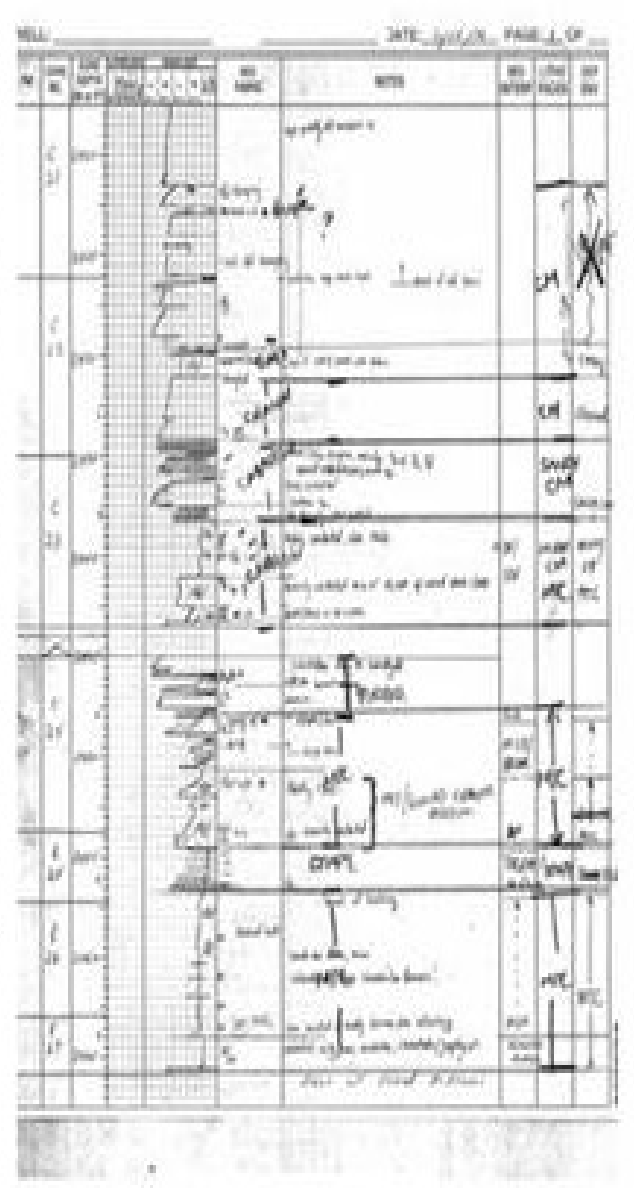

Analog

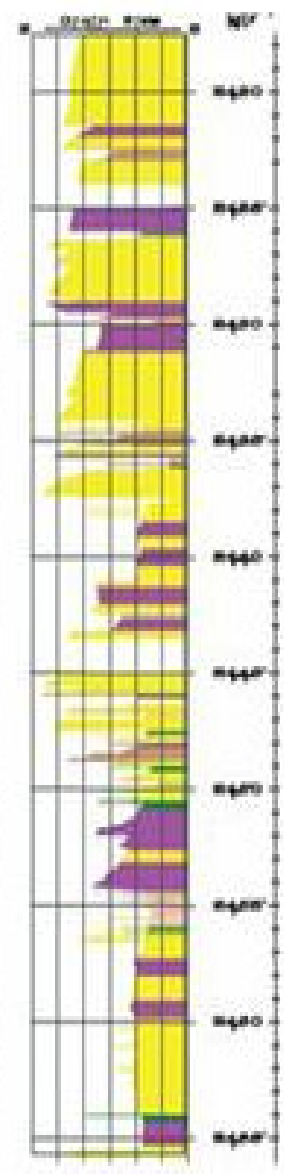

Digital

\section{Theory}

Thus, in the sand shale layers, the recorded resistivity $\left(\mathrm{R}_{\mathrm{t}}\right)$ will be equivalent to the shale and sand resistances. Therefore $\mathrm{R}_{\mathrm{t}}$ will be given by

$$
\frac{1}{R_{t}}=\frac{V_{s h}}{R_{s h}}+\frac{V_{s h}}{R_{s d}}
$$

Where;

$V_{s h}=$ Shale volume per unit volume of the formation

$R_{s h}=$ Resistivity of shale

$V_{s d}=$ Sand volume per unit volume of the formation

$$
=\left(1-V_{s h}\right)
$$

$R_{s d}=$ Resistivity of sand. 
Thus,

$\frac{1}{R_{s d}}=\left(\frac{1}{R_{t}}-\frac{V_{s h}}{R_{s h}}\right)\left(\frac{1}{1-V_{s h}}\right)$

For clean sand, saturation is quite accurately done by Archie's equation and therefore;

$$
\boldsymbol{S}_{w}=\left[\frac{\alpha R_{w}}{\phi^{m} \cdot R_{t}}\right]^{\frac{1}{n}}
$$

Where $S_{w}$ is the water saturation of the clean formation, $R_{t}$ is the corrected total electrical resistivity of formation obtain from resistivity $\operatorname{logs}, \phi$ is porosity of the rock obtained from resistivity $\log _{\mathrm{s}}, \mathrm{R}_{\mathrm{w}}$ is the water resistivity obtained from self potential (SP) logs, $\alpha$ is a constant which depends on rock type and tortuosity of the fluid path, $\mathrm{m}$ and $\mathrm{n}$ are cementation and saturation exponents which are constant (Archie, 1942).

The value of $\alpha$ is 0.6 for unconsolidated sand stones, 0.8 for consolidated sand stones, (Kamel and Mabrouk, 2002).

The shale volumes and porosity of sand lamina can be calculated using the following equations, (Thomas and Stieber, 1975).

a. For laminated shale $\left(V_{s h}=V_{L}\right)$

$$
\phi_{T}=\phi_{\max }-V_{L}\left(\phi_{\max }-\phi_{T s h}\right)
$$

b. Dispersed shale $\left(V_{s h}=V_{D}\right)$

$$
\phi_{T}=\phi_{\max }-V_{D}\left(1-\phi_{T s h}\right)
$$

c. Structural shale $\left(V_{s h}=V_{s}\right)$

$$
\phi=\left(\phi_{\max }+V_{s}\right) \phi_{T s h}
$$

d. Material balance for shale

$$
V_{s h}=\left(V_{L}+V_{D}+V_{s}\right)
$$

\section{Methodology}

Over the years, a variety of techniques have been used by the petrophysicist in the evaluation of thin, hydrocarbon-bearing sand beds. For good thin hydrocarbon-bearing sands, it is essential that we have the ability to properly evaluate them. Quite often, however, this is not the case and reservoir characterization is hampered by the lack of good quality logging data. The standard logdata-gathering technique together with their modus operandi is given in figure 2 .

Accurate interpretation of thin bed is possible with a method that uses resistivity anisotropy and high resolution borehole measurement such as borehole imaging and Nuclear Magnetic Resonance (NMR), Forsyth et al. (1993).

This paper focus on using the resistivity borehole, and the NMR imaging techniques in thin bed identification and determination of bed boundaries since conventional logs cannot be used alone to resolve thin beds or lamination. Thomas Stieber and Archie's equation was used in formation evaluation of thin bed reservoirs. Thin bed analysis using resistivity borehole image tools.

This is one method in reservoir characterization of a laminated shaly- sand 
sequence. In the absence of core data geophysicist and geologist often employ; borehole image logs in identifying thin beds quantitatively. This technique is used to enhance standard log resolution with the help of high resolution shallow resistivity log recorded by borehole imager. This technique follows the following steps/ workflow;

- Input resample depth matched SRES, $\mathrm{R}_{\mathrm{t}}, \mathrm{GR}$, RHOB and NPHI logs

- Identify the bed boundaries from SRES log.

- Identification and classification of different lithofacies.
- Creating filter for each facies.

- Application of filters to each $\log$ and generate square logs.

- Optimization of iteration

- Output sharpened RT, GR, RHOB, and NPHI logs.

- Volumetric computation of shale volume, porosity, resistivity and saturation

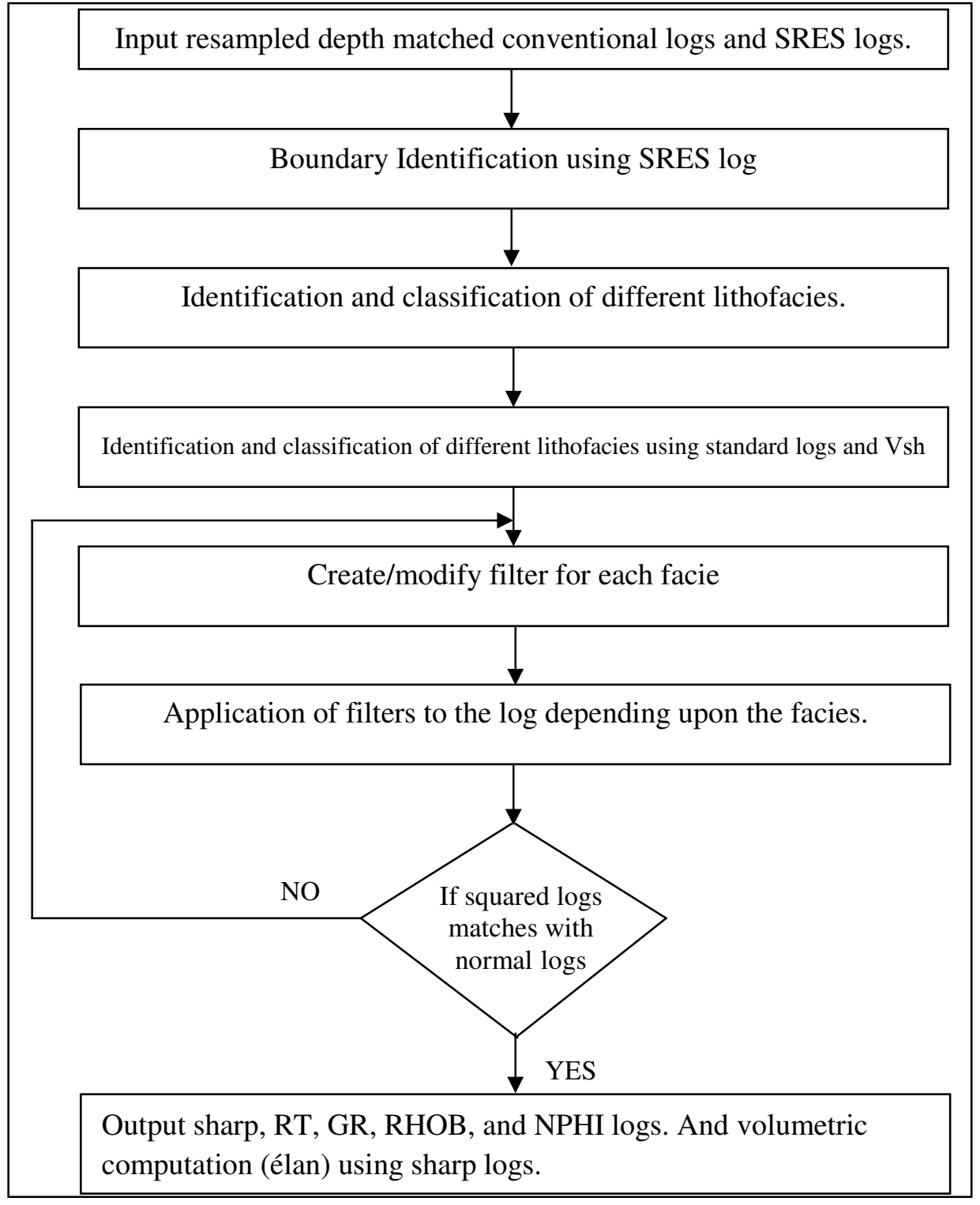

Fig 2: Thin bed analysis using Image log. 


\section{Bed Boundary Identification}

Bed boundaries are identified from inflection points in SRES data. It can be done either by software or manually. Software defines the bed boundaries based on maximum slope change (second derivative method) in SRES log.

Classification and Identification of Different Lithofacies

Lithofacies can be classified into three main lithofacies: sand, silt, shale and two auxiliary facies wet and tight. Lithofacies can be identified using normal $\operatorname{logs}$ and volume of shale. Higher resistivity indicates sands, moderate resistivity indicates silt and low resistivity indicates shale. Tight streak and hydrocarbon bearing sands can be differentiated from density-neutron and other logs. OBM invaded wet sand and silt can be differentiated by the deep resistivity curve. To differentiate low invaded water wet sand and shale both of which have low resistivity volume of shale curve can be used. Based on the threshold values of volume of shale and standard input logs, one can define a litho-facies model of sand, silt and shale. Further auxiliary litho-facies ca be defined as wet and tight based on deep resistivity and bulk density.

\section{Creating and application of filter for each facies}

For initial set of vertical filter, the data range (minimum, maximum) and average value of physical parameter for each log for each facies. If there is a large range in physical property then the whole data set can be divided into a number of zones and then the same process is to be repeated. Once the filter is created, it can be convolved with standard logs to generate the square (blocked) logs.

\section{Optimization of Iteration}

After generation of initial set of square logs optimizer would check whether the squared logs are matching with the standard log or not, if not then optimizer iteratively changes the average value for each $\log$ for each facies to get a best match.

Using the sharpened optimized data, processing is run using the core derived parameters. Clay volume is recomputed using the sharpened logs, which has gone as an input in the processing.

Shortcomings of Thin Bed Analysis using Resistivity Borehole Image Tools
- The computation is based on modelled curves, in which the facies definition is completely dependent on interpreter.

- Hard streaks are also picked as hydrocarbon bearing zone.

- Zone with sand lamina which are thinner (less than 1 foot) are over looked.

- Zones with thin shale layers are also over looked, hence over estimate of net.

\section{Nuclear Magnetic Resonance (NMR) Imaging Technique.}

The NMR imaging technique used in this research study is a physical phenomenon in which magnetic nuclei in a magnetic field absorb and reemit electromagnetic radiation. This energy is at a specific resonance frequency which depends on the strength of the magnetic field and the magnetic properties of the isotope of the atom.

A key feature of NMR is that the resonance frequency of a particular substance is directly proportional to the strength of the applied magnetic field. It is this feature that is exploited in imaging techniques. The effectiveness of NMR can also be improved using hyper polarization, and or using two dimensional, three dimensional and higher dimensional multi-frequency techniques.

NMR signal strength can be maximized if the two chosen fields are made to be perpendicular to each other.

\section{Results and Discussion}

Results of the resistivity borehole imaging technique used in this study are presented in Figure 3 below. The results show the presence of thin beds at depth of $4350 \mathrm{~m}$ and $4500 \mathrm{~m}$, thus, confirming the presence of hydrocarbon. The porosity and various sand types were revealed from the graphical analysis of the thin sand/shale in which conventional logging tools with low vertical resolution were unable to detect.

Result presented in Figure 4 below show the true formation evaluation of the thin bed values, the 'horizontal resistivity', $\mathrm{R}_{\mathrm{t}}$, 'vertical resistivity', $\mathrm{R}_{\mathrm{v}}$ and the hydrocarbon bearing thin bed. 


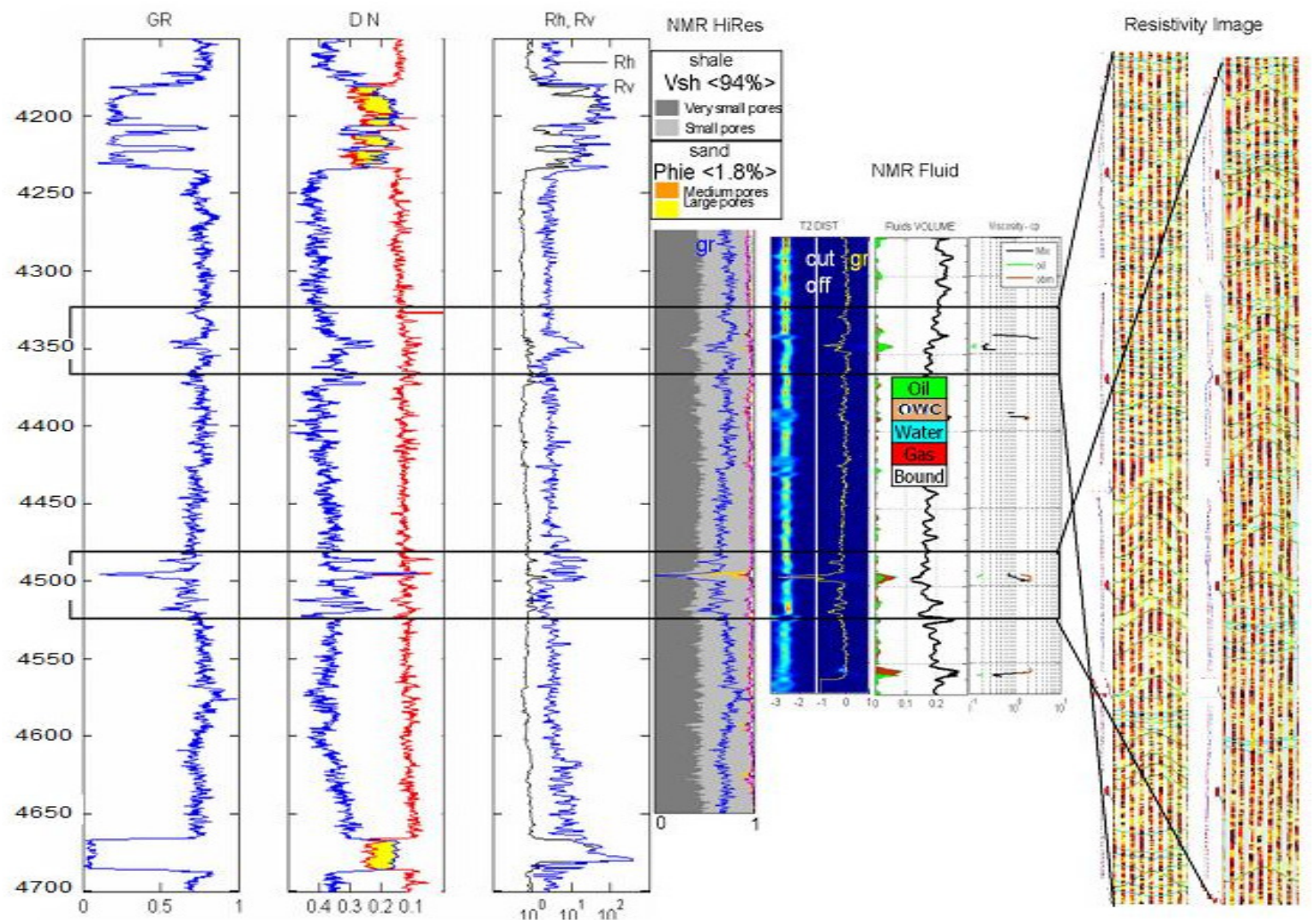

Fig 3. Graphical Analysis of thin Sand/Shale Lamination in the presence of Anisotropic Shale.

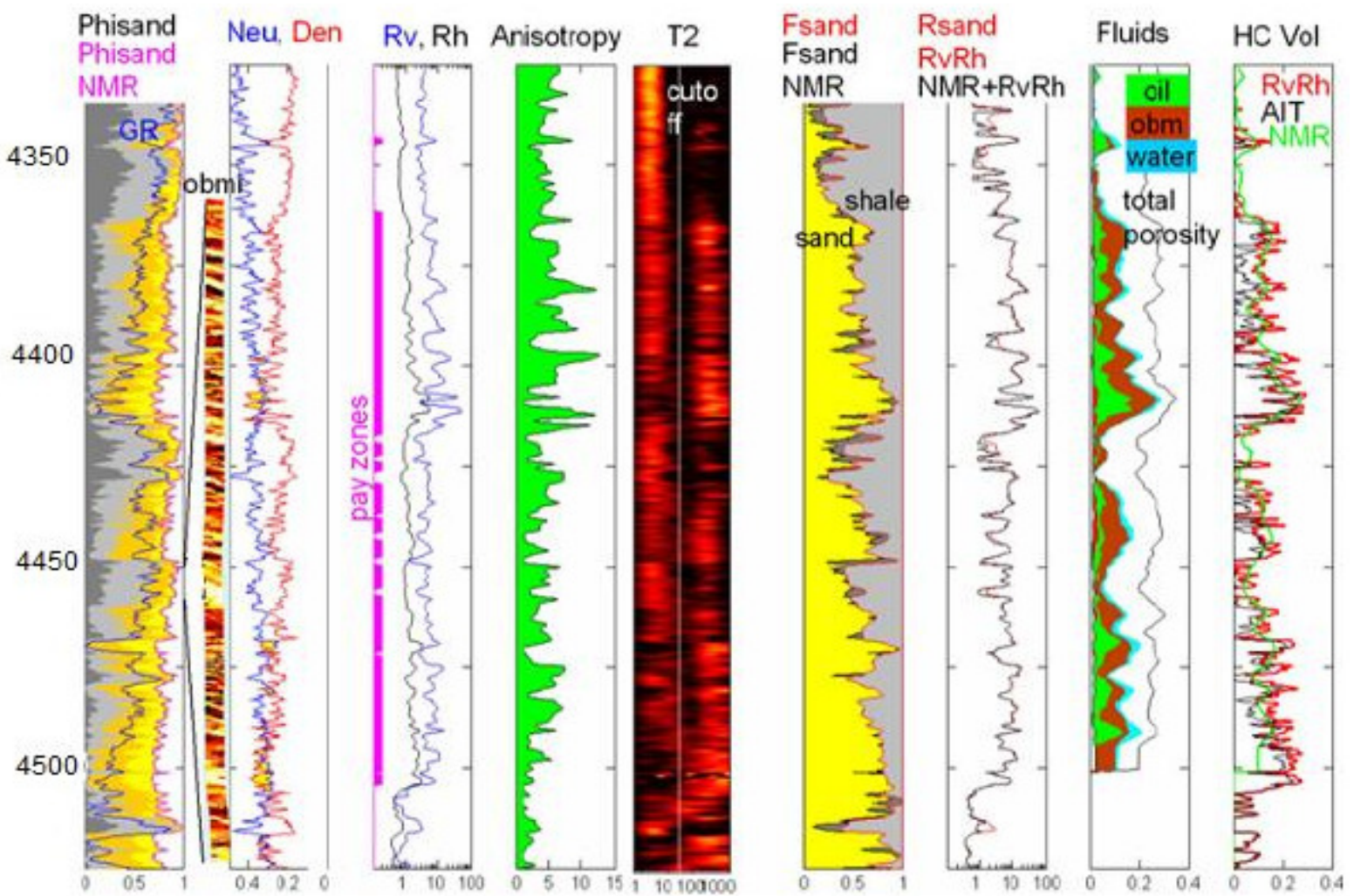

Fig. 4. Logs showing graphical Quantitative thin log analysis. 


\section{Conclusion}

In this study, we have been able to show, how the resistivity borehole and NMR imaging techniques, can be used to characterized good thin beds. If this techniques are well applied, can maximize hydrocarbon yield, unattainably obtained using the conventional logging tools.

It is recommended that laminated sand- shale should be analyzed using the Thomas Stieber and Archie's equation for formation evaluation of sand porosity and hydrocarbon saturation estimation since its use in this study yielded interesting results that are not only reliable but highly dependable. Laminated sand- shale should be calibrated with core data to get a true estimate of the Net/Gross of the hydrocarbon. Core data should also be correlated with borehole images to confirm thin bed.

Due to high cost of core acquisition, geologist and petrophysicist tend to find ways of deriving core-like geological information from borehole image logs; it is therefore recommended that image logs should form an integrated part for the characterization of thin bed reservoirs. Laminated shaly- sand analysis should be done using different approaches, since laminated shaly- sand analysis provides better control on the realistic estimation of thin bed.

\section{References}

Archie, G.E., (1942). The Electrical Resistivity
Log as an aid in Determining some Reservoir Characteristics, Transition, AIME 31, 350-366.

Claverie, M., S. Hanseu., S. Daungkaew, Z. Pickett, O. Akinsanmi, and P. Pillai, (2007), Application of NMR Logs and Borehole Images to the Evaluation of Laminated Deepwater Reservoirs; SPE 110223, (2007), Asia-Pacific Oil and Gas conference, Jakarta, Indonesia.

Forsyth, D., Nawawi, H., and Ho, T.C., (1993), Review of Techniques for the Interpretation and Evaluation of Thin Sand Sequence, Thesis SPE 25357, Presented in the SPE Asia-Pacific Oil and Gas conference, Singapore.

K. Saxena, A. Tyagi., T. Klimentos., C. Morriss, A. Mathew, (Schlumberger), 2006, Evaluating Deepwater Thin - Bedded Reservoirs with Rt Scanner, Petromin, Kuala Lumpur

Kamel, M. H., Mobarouk, W. M. (2002). An equation for Estimating Water Saturation in Clean Formation Utilizing Resistivity and Sonic Logs: Theory and Application, J. Petroleum Sci. Eng., $36,159-168$.

Saxena, K. and Klimentos, T., (2004). Field Study of Integrated Formation Evaluation in Thinly Laminated Reservoirs, SPWLA $45^{\text {th }}$ Annual Logging Symposium.

Thomas, E. C., and Stieber, S. J. (1975). The Distribution of Shale in Sandstone and its Effect upon Porosity, SPWLA $16^{\text {th }}$ Annual Logging Symposium Transactions, Paper T. 